\title{
Evasão no curso de licenciatura em geografia da Universidade Estadual do Oeste do Paraná (UNIOESTE): indagações e complexidades
}

\author{
Evasion in the geography course in geography of the state university of \\ the West of Paraná (UNIOESTE): inquiries and complexities
}

\author{
Marileni Francieli WilhelmI; Marli Terezinha Szumilo SchlosserII
}

\section{RESUMO}

A evasão escolar no ensino superior é um tema que apresenta indagações e complexidades. A necessidade de ampliar e aprofundar o estudo sobre a evasão universitária remeteu este trabalho, de modo a compreender a questão da evasão no Curso de Licenciatura em Geografia da Universidade Estadual do Oeste do Paraná (UNIOESTE), Campus Marechal Cândido Rondon. O enfoque temporal ficou limitado aos anos de 2012 a 2015, desenvolveram-se levantamentos de dados e possíveis hipóteses da evasão, a fim de caracterizar as dificuldades encontradas pelos discentes na conclusão do curso. Para o desenvolvimento do estudo, optou-se pela pesquisa qualitativa, através da técnica de estudo de caso, com a participação de discentes evadidos do Curso de Licenciatura em Geografia, por meio de entrevista/questionário semiestruturado. Nesse contexto, o número de ingressantes no curso supracitado totalizou em 146 discentes. Destes, $53 \%$ se evadiram do curso. Dos 73 discentes evadidos relativos ao enfoque temporal, 53 discentes concordaram em contribuir com a pesquisa. Uma das razões mais fortes para o abandono do curso, segundo os retornos, é a dificuldade de conciliar trabalho e universidade, pois $85 \%$ dos evadidos desenvolviam atividades remuneradas ao desistirem do curso. Outro fator é que se verifica participação reduzida dos ex-alunos na vida interna da universidade, seja por falta de tempo, seja por falta de informações sobre seu funcionamento e espaços de atuação dos alunos na instituição.

Palavras-chave: Ensino Superior; Evasão Escolar; Licenciatura em Geografia

\section{ABSTRACT}

School dropout in higher education is a topic that presents several questions and complexities. The need to expand and deepen the study on university school dropout referred this research in order to understand the issue of evasion in the Degree Course in Geography of the State University of the West of Paraná (UNIOESTE), Campus Marechal Cândido Rondon. The temporal focus was limited to the years 2012 to 2015, data surveys and possible circumvention hypotheses were developed in order to characterize the difficulties encountered by the students at the conclusion of the course. For the development of the study, we chose a qualitative research, through the case study technique, with the participation of students evaded from the Geography Degree Course, through a semi structured interview / questionnair. In this context, the number of enrollments in the above mentioned course totaled 146 students. Of these, 53\% evaded the course. Of the 73 evaded students related to the temporal approach, 53 students agreed to contribute to the research. One of the strongest reasons for dropping out of the course, according to the returns, is the difficulty of reconciling work and university, since $85 \%$ of evacuees developed paid activities when they dropped out of the course. Another factor is that there is reduced participation of former students in the university's internal life, whether due to lack of time, or lack of information about its functioning and spaces of action of students in the institution.

\section{Keywords: Higher Education; School Dropout; Degree in Geography}

IDoutoranda em Geografia, UNIOESTE, Francisco Beltrão, PR. E-mail: maryejaime@live.com ORCID: https://orcid.org/0000-0001-66823307

II Professora Associada C da Universidade Estadual do Oeste do Paraná. E-mail: marlisch20@hotmail.com ORCID: https://orcid.org/0000-0002-8490-2110 


\section{INTRODUÇÃO}

Em paralelismo com as diversas "oportunidades" (que atualmente estão em constantes incertezas) de ingressar e permanecer na universidade, está alocado também o fenômeno do alto índice de evasão no ensino superior. Ribeiro (2005) destaca que a evasão universitária vem se impondo, ao longo do tempo, como realidade mais ostensiva no âmbito do ensino de graduação.

A evasão dos discentes tem sido motivo de preocupação das inúmeras instituições de ensino, públicas ou privadas, nos diversos níveis (fundamental, médio e superior) e nas diferentes modalidades de ensino (educação de jovens e adultos, educação profissional e educação especial). Ao tratar de evasão escolar, não é possível considerar apenas o feito de livrar, evitar, escapar, esquivar, mas um vasto conjunto de questões que vão além da simples desistência dos alunos.

Nesse sentido, para discorrer sobre a problemática enunciada, procurou-se compreender e verificar os motivos da evasão escolar no ensino superior e nas licenciaturas. Para tanto, focou-se no estudo de caso do Curso de Geografia da Universidade Estadual do Oeste do Paraná (UNIOESTE), Campus Marechal Cândido Rondon. O debate que originou o referido artigo teve como premissa a análise e reflexão sobre a evasão universitária. O estudo é oriundo da pesquisa desenvolvida em conjunto com os integrantes do Laboratório de Ensino de Geografia (LEG) e Linha/Grupo de Pesquisa/Ensino e Práticas de Geografia (ENGEO) da UNIOESTE.

Com a pesquisa buscou-se embasamento teórico na área educacional e análise da evasão universitária em outras áreas, de modo a integrar esse entendimento ao foco do estudo no Curso supracitado. O enfoque temporal ficou limitado aos anos de 2012 a 2015, desenvolveram-se levantamentos de dados e possíveis hipóteses da evasão, a fim de caracterizar as dificuldades encontradas pelos discentes na conclusão do curso.

Enquanto hipóteses, diversas são as questões que sugerem a interferência na profissão. Baixos salários? Falta de perspectiva? Problemas de indisciplina na sala de aula? Dificuldades em associar a graduação com a vida social? A pressão social e familiar para adentrar o ensino superior rapidamente? Baixo desempenho no ensino médio? Imaturidade no momento da escolha do curso? Questão de identidade com a área educacional? 
Acredita-se que algum ou alguns desses fatores podem ser considerados como marco fundamental na desistência de número expressivo de acadêmicos, visto que ingressar em um curso superior se caracteriza uma escolha difícil, envolve decisões de âmbito pessoal e material. Dessa maneira, entender a evasão no ensino superior implica conhecer e compreender os processos de mudanças pelos quais passam os discentes durante o período de formação universitária.

Dessa forma, a escolha do tema decorreu da necessidade de desenvolver estudos específicos nesta área, na tentativa de contribuir com a melhoria do curso, uma vez que as informações e dados obtidos foram dispostos aos representantes locais da Associação de Geógrafos Brasileiros (AGB), Centro Acadêmico (C.A), Colegiado do curso, bolsistas do Programa Institucional de Bolsas de Iniciação à Docência (PIBID), e docentes de modo a organizar ações concretas para diminuir a evasão.

Em relação ao tipo de pesquisa, quanto à sua abordagem, é qualitativa, ainda que lide com dados numéricos enquanto variáveis que sustentam análise. A pesquisa qualitativa é caracterizada pela coleta de variados tipos de dados e, de acordo com Gil (2008), esse processo de análise e interpretação pode, naturalmente, envolver diferentes modelos de análise. Todavia, é natural admitir que à análise dos dados seja de natureza predominantemente qualitativa.

Conforme citado anteriormente, foram utilizadas, na construção desta pesquisa, informações qualitativas, informações que favorecem a compreensão dos fenômenos de maneira natural, "[...] de modo a auxiliar a compreensão das relações entre os indivíduos, seu contexto e suas ações" (ANDRÉ, 1983, p. 66). Assim, portanto, a análise qualitativa preocupa-se com aspectos da realidade que não podem ser quantificados, centrando-se na explicação e na compreensão da dinâmica nas relações sociais. Segundo Minayo (2001), esse modo de pesquisar trabalha com motivos, com causas, com valores e com atitudes, além de aprofundar as relações dos processos e dos fenômenos.

Quanto aos objetivos, classificou-se como exploratória esta pesquisa, o que significa que, segundo Gil (2008), visa proporcionar familiaridade com o problema, para, se possível, torná-lo explícito ou construir hipóteses. Em relação aos procedimentos, o trabalho assume a forma de estudo de caso, com a participação de discentes evadidos do Curso de Licenciatura em Geografia, por meio de 
entrevista/questionário semiestruturado. Nesse sentido, visto que vários sujeitos da pesquisa residem em diferentes municípios do Paraná, as entrevistas/questionários foram realizadas através do e-mail, do Facebook, via Whatsapp e pessoalmente, através da gravação de áudio.

A partir desse parâmetro, ressalta-se que no referido artigo, está detalhado levantamento bibliográfico de informações e dados. Foram localizados e considerados livros, artigos, teses de Doutorado e dissertações de Mestrado para contextualizar e entender a evasão no ensino superior, em especial nos cursos de licenciaturas no Brasil. Na primeira parte, apresentou-se discussões acerca dos conceitos e índices da evasão no ensino superior, a partir especialmente da Comissão Especial para o Estudo da Evasão (1995), do Instituto Lobo (2012), dados do Mapa Ensino Superior do Brasil (2015) e do Instituto Nacional de Estudos e Pesquisas Educacionais Anísio Teixeira (INEP). Os dados destacam os índices de evasão dos cursos presenciais na rede privada, pública e nos cursos de Educação a Distância (EAD). Ainda, buscou-se aproximar informações do objeto de pesquisa para compreender o que configura a evasão escolar para a UNIOESTE.

Na sequência, desenvolveu-se observações sobre possíveis determinantes da evasão nas Licenciaturas, percebeu-se a importância de se conhecerem não apenas os índices, os percentuais, os números, mas os motivos, as dificuldades e desafios na conclusão do curso de graduação. Entre os motivos, conforme informações da Comissão Especial para o Estudo da Evasão (1995) e o Ministério da Educação e Cultura (MEC) (1996) destacam-se três fatores: individual do aluno, internos e externos.

$\mathrm{Na}$ última parte foram realizadas as análises dos dados obtidos (entrevistas e questionários) e uma reflexão sobre a evasão no Curso de Licenciatura em Geografia da Unioeste/Campus de Marechal Cândido Rondon. A partir desse contexto, tratou-se de apontar os principais motivos relacionados à desistência no curso.

\section{EVASÃO: CONCEITOS E ÍNDICES}

A evasão estudantil é fenômeno complexo, que abrange as Instituições de Ensino Superior (IES) no mundo contemporâneo. No Brasil, antes da década de 1990, o tema da evasão nas universidades era vago, quantidade baixa de pesquisas havia 
sido desenvolvidas em torno dessa proposição. A partir de 1995, discussões amplas manifestaram-se, especialmente ao instituir-se a "Comissão Especial para o Estudo da Evasão" pela Secretaria de Educação Superior/Ministério da Educação e do Desporto (SESU/MEC). A ideia dessa Comissão surgiu pelos baixos índices de diplomação registrados, com evasão média nacional de $50 \%$ dos estudantes nas Instituições Federais de Ensino Superior (IFES).

Segundo a Comissão, os motivos para a pesquisa destacam-se pela necessidade de identificação das causas específicas e gerais relativas à evasão. Para promover as discussões foram citadas:

Experiências institucionais que já vêm influenciando na redução desses índices, tais como as medidas administrativas tomadas pela UNICAMP, extinguindo a segunda opção no Concurso Vestibular; o papel da Fundação Universitária Mendes Pimentel da UFMG que faz um trabalho de apoio ao estudante, concedendo bolsas, orientando os alunos; os Cursos Cooperativos, resultantes de convênios entre Universidade e Empresa, a exemplo de várias universidades inglesas, que desenvolvem em três quadrimestres do ano, cursos de engenharia intercalando períodos acadêmicos e de estágio nas empresas. Alguns membros da Comissão trouxeram outros exemplos de atividades acadêmicas que facilitam a relação teoria/prática e aprofundam o conhecimento profissional do aluno. (COMISSÃO, 1995, p. 13).

Dos trabalhos da Comissão resultou um relatório, intitulado "Diplomação, retenção e evasão nos cursos de graduação em Instituições de Ensino Superior Públicas", apresentado no segundo semestre de 1997. Foram analisadas as taxas de evasão, diplomação e retenção dos discentes de cursos superiores públicos no Brasil. Nesse estudo, contudo, não foi possível levantar as causas e/ou motivações para à evasão, tampouco os fatores a influenciar as taxas de diplomação e de retenção (COMISSÃO, 1995).

Conforme destaca a Comissão, as razões apontadas para 0 não desenvolvimento da pesquisa qualitativa revelam o fato de à abrangência da pesquisa ser nacional, e número expressivo de universidades não terem disponibilizado dados sistematizados e informatizados. Assim, esse processo:

Exigiu o treinamento das pessoas envolvidas e ocasionou inúmeras reuniões regionais e nacionais, demandando mais tempo para ultimar o estudo. Terceiro, pela ausência de qualquer tipo de apoio financeiro e logístico do MEC ou de outra agência de fomento à pesquisa, o que acarretou um esforço adicional para os professores envolvidos e elevados custos para as universidades participantes, principalmente aquelas que integravam a Comissão. A comissão então afirmou que exatamente por isto sua complexidade e abrangência vêm sendo, nos últimos anos, objeto de estudos e análises, especialmente nos países do Primeiro Mundo. Tais estudos têm demonstrado não só a universalidade do fenômeno como a 
relativa homogeneidade de seu comportamento em determinadas áreas do saber, apesar das diferenças entre as instituições de ensino e das peculiaridades sócioeconômico-culturais de cada país (COMISSÃO, 1995, p. 14).

Dessa forma, o estudo supracitado apresenta lacunas, além dos seus limitados fundamentos quanto às causas e às consequências da evasão. Assim, ainda que o tema evasão no ensino superior esteja presente em pesquisas (teses, dissertações, monografias, Comissão Especial para o Estudo da Evasão), verifica-se a carência de materiais e de metodologia que possam delimitar com segurança o índice de evasão.

O INEP disponibiliza de maneira vaga as informações sobre a saída de discentes, não são apresentados índices e causas da evasão. Ao considerar esse cenário, se os dados fossem demonstrados de forma clara e objetiva, com detalhamentos conceituais e procedimentais em relação à metodologia, facilitaria a compreensão sobre a evasão no ensino superior. Dessa maneira, parte dos conceitos e dos dados relativos à evasão no ensino superior é encontrada por meio das pesquisas acadêmicas dentro das diversas áreas do ensino, além de documentos, relatórios, entrevistas. No âmbito dessa perspectiva:

Estudar a Evasão deveria ser uma política governamental geral voltada à qualidade acadêmica e, também, à responsabilidade do uso dos recursos (públicos e privados), desde que essa política seja entendida como a realização de processos e análises (documentados, sistematizados e divulgados, incluindo os resultados das ações realizadas) motivados e/ou incentivados, explicitamente, por órgãos de governo gestores ou fiscalizadores das IES públicas e privadas para essas duas finalidades, (LOBO, 2012, p. 7)

No decorrer da pesquisa, durante as consultas aos referenciais teóricos relativos à evasão no ensino superior, constatou-se relação multidisciplinar com objeto de estudo amplo, em variadas áreas do conhecimento: humanas, biológicas e sociais. O Ministério da Educação e Cultura (MEC) conceitua evasão do curso como "[...] saída definitiva do curso de origem sem conclusão, ou a diferença entre ingressantes e concluintes, após uma geração completa" (BRASIL, 1997, p. 19).

Silva Filho (2007), em pesquisa relativa a esse fenômeno, revelou que a maioria das instituições não contempla programa regular de combate à evasão, portanto, não dispõe planejamento de ações e acompanhamento de experiências e resultados. Polydoro (2000), aponta que é necessário intervir através de mediações que previnam e controlem os fatores que levam à evasão. Para ocorrer esse estudo institucional de forma eficiente, os dados oficiais e características da evasão devem 
ser explicitados de maneira concreta, em conjuntura com pesquisas consistentes, por órgãos competentes ou pela própria instituição de ensino. Assim:

Poderia colaborar para minimizar os efeitos da evasão e se tornar em um dos meios de mudança da cultura acadêmica, seja no trabalho docente, na gestão das Instituições, nas redefinições curriculares, entre outras dimensões da estrutura do Ensino Superior. (BAGGI e LOPES, 2011, p. 365).

Diante dessa configuração, de acordo com dados do Mapa Ensino Superior do Brasil 2015, a taxa de evasão anual em 2013 (Figura 1) dos cursos presenciais atingiu o índice de $24,9 \%$, sendo $27,4 \%$ na rede privada e $17,8 \%$ na pública. Nos cursos Educação a Distância (EAD), no mesmo ano, o índice chegou a 28,8\%, sendo 29,2\% na rede privada e $25,6 \%$ na pública.

\section{Figura 1 - Evasão no ensino superior em 2013 - Brasil}

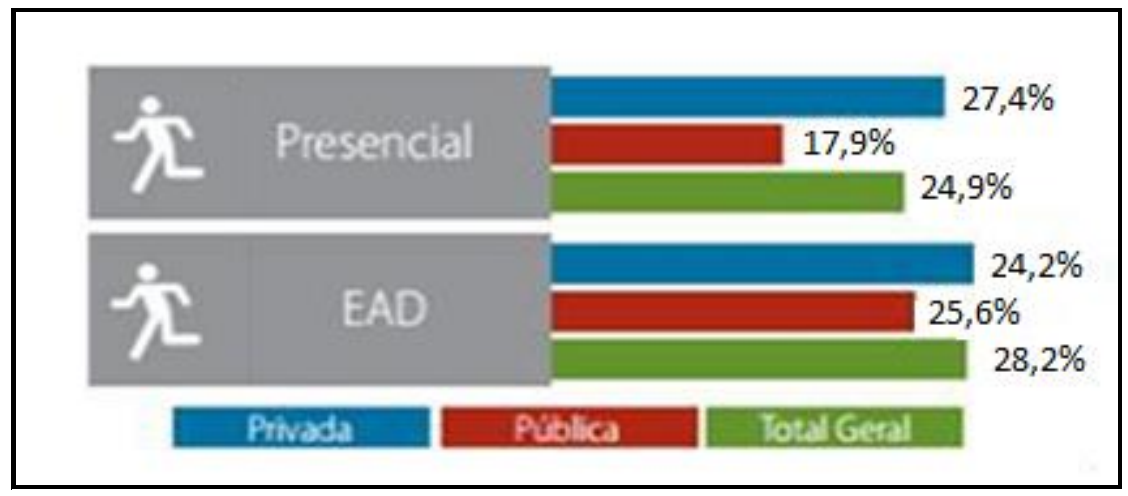

Fonte: MAPA ENSINO SUPERIOR DO BRASIL, 2015

A taxa de evasão é calculada com base nos discentes desistentes em relação ao total de matriculados. Na rede privada, a diferença entre as modalidades de ensino presencial e Educação a Distância (EAD) permaneceu em 1,8 pontos percentuais, mas na rede pública o percentual foi maior e atingiu 7,8 pontos (INEP, 2014).

Em 2013, a taxa de evasão anual dos cursos presenciais no Paraná alcançou $23,5 \%$, sendo $26,3 \%$ na rede privada e $17,2 \%$ na pública. Nos cursos EAD, o índice de evasão anual chegou a $30,6 \%$ na rede privada e a $22,9 \%$ na pública. (MAPA ENSINO SUPERIOR DO BRASIL, 2015).

No estado do Paraná, o Censo Acadêmico das Universidades Estaduais do Paraná é desenvolvido pela Secretaria da Ciência, Tecnologia e Ensino Superior 
(SETI). Segundo dados do Censo 2012, a problemática da evasão no ensino superior é sentida nas diversas Universidades Estaduais.

Diante dos olhares e perspectivas sobre evasão no ensino superior, uma vez que as particularidades das diferentes IES sobre a questão se mostram diversificadas, buscou-se aproximar informações do objeto de pesquisa para compreender o que configura para Unioeste a evasão escolar. Assim, de acordo com a Universidade:

Art. 93 do Regimento Geral Resolução 028/2003-COU de 2 de abril de 2003 e alteração realizada através da Resolução 069/2004-COU, de 3 de dezembro de 2004. A saída do aluno pode ocorrer por iniciativa própria, através de requerimento, ou compulsoriamente quando o acadêmico: a) não integralizar, no prazo máximo, o currículo do seu curso; b) não solicitar prorrogação do prazo de integralização do seu curso; c) abandonar o curso por mais de um ano letivo; d) não confirmar matrícula, nas datas previstas no calendário. (UNIOESTE, 2004, p. 9).

Dessa forma, a evasão escolar pode ocorrer por meio de requerimento formalmente emitido pelo acadêmico ou por ato administrativo, oriundo da IES: "É considerado evadido o aluno que se desliga de um dado curso e efetua ingresso em outro, por meio de novo concurso vestibular, tendo, no Registro Acadêmico anterior, o histórico de Cancelamento por Abandono" (CASTRO, 2013, p. 22).

Na IES em questão, quando ocorrer abandono de curso, o discente pode, em época especificada do edital, solicitar reabertura de vaga, sendo que, extrapolado esse período, no ano seguinte ocorre cancelamento por abandono, perdendo-se, assim, o vínculo do acadêmico com a Unioeste.

Nesse contexto, salienta-se que a evasão é "[...] comparável às doenças chamadas de silenciosas, pois nem sempre há indicadores prévios de que vá ocorrer, ou já esteja em processo" (LOBO, 2012, p. 12). Uma das formas de verificar o problema é a prevenção, de modo a verificar e acompanhar os alunos que começam a faltar às aulas ou que obtêm notas baixas, e não procuram apoio ou solução. Assim:

Estes casos vão redundar exatamente nos alunos que abandonam o curso/IES sem aviso ou explicação. Esses alunos podem até tê-los, mas geralmente como consequência, e não causa, de seu desinteresse em permanecer estudando no curso/IES atual. (LOBO, 2012, p. 12).

Conforme aponta Polydoro (2000), essa intervenção é possível através de mediações que previnam e controlem os fatores que levam à evasão. Dessa maneira, através da análise, da compreensão integrada, além do entendimento entre as partes 
(universidade e discente), pode-se desenvolver a articulação de ações institucionais e sociais para a promoção contínua do processo de ensino-aprendizagem.

Para ocorrer esse estudo institucional de forma eficiente, os dados oficiais e características da evasão devem, contudo, ser explicitados de maneira concreta, em conjuntura com pesquisas consistentes, por órgãos competentes ou pela própria instituição de ensino.

\section{POSSÍVEIS DETERMINANTES DA EVASÃO NAS LICENCIATURAS}

A evasão na educação superior está se caracterizando progressiva no contexto educacional. Diante dos dados, considerados alarmantes, instituições de ensino superior estão deparadas com a evasão nos diversos cursos, inclusive os de licenciaturas.

Com base nos questionamentos tratados no item anterior, percebe-se a importância de se conhecerem os motivos da evasão nas licenciaturas, não apenas os índices, os percentuais, os números, mas as informações concretas sobre as dificuldades e os desafios dos discentes em concluir o curso de graduação. Medir a evasão não se trata só verificar um "saldo de caixa", ou seja, quantos alunos entraram menos quantos saíram, mas quem entrou, quem saiu e por quais razões, para que seja possível evitar outras perdas pelos mesmos motivos com ações que gerem mudanças e essas só acontecem se ocorrer o entendimento do que está ocorrendo (LOBO, 2012, p. 8). Em relação a esse contexto, destaca-se que:

A evasão dos cursos superiores tem sido motivo de estudos por várias áreas do
conhecimento e sobre a qual os gestores universitários deveriam buscar mais
informações e dados, como se faz em qualquer atividade científica quando se quer
resolver ou até entender um problema. Para isso, é fundamental que os gestores e
professores façam uma pergunta e respondam a si próprios: a evasão é sempre
culpa do aluno? Se a resposta for não, então vamos tratar do assunto com a
importância que ele merece. Se a resposta for sim, mesmo assim é preciso tratar o
problema com a mesma ênfase, já que suas consequências envolvem todos os que
participam do processo de ensino, incluindo instituições e governo. (COMISSÃO,
1995, p. 60 ).

Dessa maneira, na formação universitária, compreender a evasão como processo intricado, composto por fatores econômicos, culturais, sociais e não menos acadêmicos, implica superar a visão de o problema ser apenas o discente ou do discente. Os índices de diplomação e de desistência devem ser analisados em conjunto, com dados que possam nortear à identificação dos problemas relacionados 
e fortificar a adoção de medidas pedagógicas e institucionais capazes de solucionálos.

Os motivadores da evasão nas licenciaturas estão vinculados praticamente aos mesmos motivos da evasão nos demais cursos de graduação. Entretanto, particularidades agravam os cursos de licenciaturas. Entre os diversos citados, Adachi (2009) aponta que:

A evasão pode ser atribuída a uma série de fatores, dentre eles: baixo prestígio da profissão, baixos salários, dificuldades financeiras dos estudantes para permanecerem no campus, qualidade pedagógica dos docentes, pouca atratividade dos cursos, currículos inchados, repetitivos e desarticulados, distanciamento entre teoria e prática, matematicidade dos cursos, baixa qualidade do ensino médio que contribuem para a mobilidade, se não para a exclusão. (ADACHI, 2009, p. 35).

Diante dos múltiplos olhares e das diversas perspectivas, quais são os motivos, as causas da constante evasão nos cursos de licenciaturas?

Como hipóteses motivadoras da evasão, de maneira geral, destacam-se três fatores: individual do aluno, internos e externos (MEC, 1996; COMISSÃO ESPECIAL, 1995). Em concordância com as características salientadas pela Comissão Especial, o MEC destaca que os fatores característicos individuais do estudante referente à evasão estão relacionados às habilidades de estudo, personalidade, formação escolar anterior, escolha precoce da profissão, dificuldades pessoais de adaptação à vida universitária, desencanto com o curso escolhido, dificuldades recorrentes de reprovações ou baixa frequência e desinformação a respeito da natureza dos cursos (MEC, 1995).

Assim, a ausência de informação sobre o curso (seja pela falta de o aluno buscar informar-se, seja por carência de informações por parte da instituição de ensino) e sobre a carreira a ser seguida gera, em alguns casos, insatisfação com o curso frequentado. Outro fator é o desencanto e a desmotivação em continuar o curso escolhido como segunda ou terceira opção, situação que ocorre frequentemente em instituições que permitem que o candidato faça o vestibular para mais de um curso. Em determinados casos, alunos se matriculam apenas para cursar a educação superior ou como meio para alcançar o curso efetivamente desejado, através de transferência interna ou transferência externa (MEC/ SESU, 1997). Dessa forma, à medida que esses alunos se dão conta de que a escolha do curso não condiz com as expectativas, eles efetuam o abandono. 
É de significativa relevância considerar igualmente o peso dos fatores internos, os conhecidos como intrauniversitários, desencorajadores em muitos casos. Por exemplo, problemas relacionados a currículos e aos Projetos Políticos Pedagógicos (PPPs) de cursos de graduação demasiado extensos, estratificados, rígidos, conservadores e desatualizados. Estão relacionados com o curso e instituição, como horário do curso, matriz curricular, mudança de currículo e sistema de avaliação, entre outros. Caracteriza-se por aspectos que mensuram a insatisfação do acadêmico com os métodos de avaliação desenvolvidos pelos docentes, com a deficiência didática pedagógica dos professores e a baixa qualidade no atendimento.

Paralelamente a esses aspectos encontram-se as questões de caráter didáticopedagógico. São questões que se apresentam vinculadas a metodologias consideradas tradicionais, ancoradas na transmissão e na repetição; ou são questões contra a atuação de docentes pouco comprometidos, seja com o ensino de graduação ou com projetos de atualização dos conteúdos necessários à formação acadêmica e profissional dos estudantes.

Nesse contexto, determinados conteúdos relacionados às áreas ou às disciplinas específicas não se conectam com as práticas formadoras de professores, tornando essa formação desarticulada, fragmentada, gerando discursos negativos sobre a função da escola e também sobre a profissão de professor.

Em relação aos fatores externos, podem ser classificados como prestígio social da profissão, as possibilidades de progressão profissional ou a tradição de algumas carreiras, pressões familiares, além dos aspectos vinculados às dificuldades financeiras do discente, interferem diretamente na permanência ou no abandono do curso.

Cabe observar que se justifica o fato de parcela significativa desses discentes apresentarem situação econômica desfavorecida, em termos de renda familiar ou pessoal. Pontos-chave, como perspectivas de remuneração e possibilidades de emprego em um país constantemente assolado por crises econômicas, fazem com que discentes, mesmo se sentindo vocacionados para essa profissão, tendam a mudar de curso em função das potenciais dificuldades profissionais vislumbradas (COMISSÃO, 1995). Assim, em cursos de licenciatura, questões externas influenciam constantemente os jovens universitários na continuidade ou não dos estudos. 
Dessa forma, pode-se considerar que há tendência de evasão permanente nos cursos de licenciatura em virtude de que a atividade docente se tem mostrado "pouco atrativa". Gaioso (2005) destaca que as licenciaturas estão marcadas pela falta de prestígio social e econômico. As precárias condições de trabalho, a infraestrutura escolar inadequada à aprendizagem, a insegurança nas escolas e a falta de perspectivas na carreira são fatores que contribuem para o abandono. Em consequência, um dos resultados passa a ser a falta de professores no mercado e evasão em cursos de licenciatura fazendo prever maior carência futura de docentes. Um fator que influencia nessa decisão são as condições de trabalho (GADOTTI, 1981).

De acordo com Hickmann (2007), uma profissão que não é valorizada, não possui status, e esse diferencial negativo pode interferir diretamente os estudantes na escolha e na permanência no curso. Assim, ao surgirem novas oportunidades de cursos considerados "melhores", os acadêmicos abandonam as licenciaturas.

Ao refletir sobre a profissão "Professor" na atualidade, sugerem-se problemas político-econômicos, sobretudo, a partir do golpe parlamentar de 2016. Diversos ataques direcionados ao sistema educacional brasileiro vêm sendo constituídos, reiteram-se, "as estratégias do passado da classe dominante brasileira para interromper conquistas, ainda que parciais, dos movimentos sociais, sindicatos, instituições científicas e culturais historicamente empenhadas na luta por uma sociedade mais justa" (FRIGOTTO, 2017, p. 20).

É neste processo que um novo modelo político e ideológico de administração se firmou. Ressalta-se a negligência dos governantes na formulação das políticas públicas educacionais, caracterizando-se pela proposta neoliberal, tendência para a privatização e mercantilização do ensino. Assim, salienta-se que:

[...] a privatização da política educacional pelo setor privado mercantil e, de outro, o ataque através da censura do conteúdo educação pública, via bancada religiosa no Congresso e de setores neoconservadores da sociedade, vêm se articulando amplamente com instituições globais, disputando projetos societários por dentro da educação. (PERONI; CAETANO; LIMA, p.429, 2017).

De fato, os interesses econômicos se sobressaem aos educacionais, tornando a educação como ponto estratégico para garantia, manutenção e ampliação do sistema capitalista. Esse fato revela que a educação é revestida por investimentos privados de tal modo a promover a comercialização do ensino, ao mesmo tempo em que se 
pretende desenvolver a formação acadêmica (WILHELM, 2019). Assim, o sistema capitalista "sempre recorre a novas estratégias para a manutenção do status quo, ou seja, a introdução do neoliberalismo que passa a ter um papel mundial, ocasionando profundas mudanças nas sociedades em geral e especificamente no trabalho e na educação (PONTUSCHKA, 2013, p. 435).

Inseridas na racionalidade técnica da globalização neoliberal, todavia, políticas, apresentam-se às instituições de ensino numa perspectiva instrumental e pragmática, na qual as normas são apreendidas em seu aspecto funcional e burocrático, em que se busca a mera compreensão do 'como fazer' para dar conta do controle exercido pelo governo. Desse modo, as mudanças curriculares ocorrem apenas na dimensão estrutural, com a introdução/exclusão de disciplinas e áreas de conhecimento, aumento ou redução de tempos e inclusão de aparatos tecnológicos, sem vislumbrar, nessa reestruturação, um projeto voltado para a emancipação dos sujeitos que educam e/ou para promover mudanças sociais significativas. (SANTIAGO; CALLAI, 2014, p. 19-20).

Os efeitos desses sistemas aparecem em programas. reformas desenvolvidas em âmbito federal (Brasil) e estadual (Paraná). Nessa perspectiva, "não são debatidas com associações de professores, sindicatos, pesquisadores, e estão sendo aprovadas sob sua resistência, como no caso da Reforma do Ensino Médio, da Base Nacional Comum Curricular (BNCC) e do Escola Sem Parido (ESP)".(PERONI; CAETANO ; LIMA, p.417, 2017).

A Reforma do Ensino Médio firmou-se através da Lei 13.415 de 16.2.2017, articulada a Medida Provisória (MP) 746/2016, alterando o Ensino Médio unilateralmente e sem diálogo com a sociedade. Entre os aspectos presentes no texto da MP, salienta-se "a extinção da obrigatoriedade de quatro disciplinas - Sociologia, Filosofia, Artes e Educação Física - e a possibilidade de atribuição do exercício da docência a pessoas com "notório saber" em alguma especialidade técnicoprofissional" (FERRETI; SILVA, p. 85, 2017). Ainda, constatou-se que:

[...] a proposta aprovada corresponde ao intento do atual governo de ajustar a educação aos desígnios do capitalismo financeiro, buscando formar uma mão de obra dócil e a baixo custo. Para tanto, na contramão da tendência atual de empreender a unificação do ensino médio, fragmenta-o em cinco itinerários, argumentando com o princípio da flexibilidade que permitiria aos alunos a livre opção pelo itinerário que correspondesse aos respectivos projetos de vida, o que, na verdade, camufla a intenção de induzir a grande maioria à opção pelo quinto itinerário, ou seja, formação técnica e profissional. com efeito, como atribuir a 
adolescentes na faixa dos 15 anos de idade a opção livre e consciente por um itinerário formativo segundo seu próprio projeto de vida? de fato, essa reforma retrocede à década de 1940 , com as reformas capanema, quando o ensino médio foi dividido entre o ensino secundário, "destinado às elites condutoras" - na reforma atual, correspondente aos quatro primeiros itinerários -, e o ensino técnico-profissional, subdividido nos ramos industrial, comercial e agrícola, destinado ao povo conduzido (SAVIANI, p. 787, 2018).

Segundo a nota pública da Associação Nacional de Pós-Graduação e Pesquisa em Educação (ANPEd) sobre a MP do Ensino Médio, o princípio do Ensino Médio como direito de todo cidadão a uma formação plena para a cidadania e o trabalho está fragilizado, visto que viabiliza canais para a mercantilização da escola pública e evidencia a face mais perversa do golpe contra a sociedade brasileira, os estudantes, seus professores e a educação pública.

A BNCC, aprovada pela Resolução CNE/CP n. ${ }^{\circ}$ 2, de 22 de dezembro de 2017, constitui-se como um documento que apresenta conjunto de orientações para homogeneizar os currículos das escolas públicas e privadas de ensino infantil, fundamental e médio do Brasil. Ressalta-se, de acordo com a professora Maria do Carmo Martins, líder do Grupo de Pesquisa Memória, História e Educação (Memória) da Faculdade de Educação (FE) da Unicamp, as propostas da BNCC contemplam os interesses dos empresários da educação, como produtores de softwares e materiais educativos. "Um olhar atento verificará que a Base é muito tímida em relação a direitos sociais, a ações de inclusão e a questões de gênero, posição que está em consonância, por exemplo, com a postura daqueles que defendem a Escola sem Partido" (MARTINS, 2017, p.1). Ao refletir sobre a BNCC e os possíveis impactos das medidas previstas no documento, destaca-se:

Ao mesmo tempo em que afirma que a Base não é o currículo, mas sim uma diretriz para a elaboração deste, o texto entra em minúcias acerca das finalidades e objetivos do ensino. Há aí uma inversão. Existe uma consolidada crítica à visão tradicional dos currículos organizados por objetivos. E a BNCC insiste em consolidar essa visão de desenvolvimento curricular, ignorando que é na dinâmica da cultura que as seleções são feitas, de modo que sejam socialmente válidas para a comunidade de estudantes e educadores, conferindo sentidos ao processo educativo (MARTINS, 2017, p.1).

Nessa configuração, o documento coloca em segundo plano a expressividade do processo de escolarização. Assim, "tira o cotejo da aprendizagem do encontro pedagógico, que é algo que pode modificar qualitativamente a vida das pessoas, e o 
coloca sobre o resultado. Isso produz uma estandardização da educação, baseada em uma visão também padronizada de qualidade" (MARTINS, 2017, p.1).

Paralelamente a isso, surge o Movimento Escola Sem Partido (ESP), com ideais solidificados no combate às chamadas "doutrinação ideológica" e "ideologia de gênero". È constituído por "partido da intolerância com as diferentes ou antagônicas visões de mundo, de conhecimento, de educação, de justiça, de liberdade; partido, portanto, da xenofobia nas suas diferentes facetas: de gênero, de etnia, da pobreza e dos pobres etc" (FRIGOTTO, 2017, p. 31). A proposta do ESP tem como elemento fundamental a censura, de modo a tentar interditar o trabalho dos professores, e que tem como foco a direção da educação pública brasileira, decidindo sobre quais conhecimentos e conteúdos deverão ser desenvolvidos no espaço escolar. Assim:

O que propugna o Escola sem Partido não liquida somente a função docente, no
que a define substantivamente e que não se reduz a ensinar o que está em
manuais ou apostilas, cujo propósito é de formar consumidores. A função docente
no ato de ensinar tem implícito o ato de educar. Trata-se de, pelo confronto de
visões de mundo, de concepções científicas e de métodos pedagógicos,
desenvolver a capacidade de ler criticamente a realidade e constituírem-se sujeitos
autônomos. A pedagogia da confiança e do diálogo crítico é substituída pelo
estabelecimento de uma nova função: estimular os alunos e seus pais a se
tornarem delatores (FRIGOTTO, 2017, p. 31).

Destaca-se ainda outro fator negativo em anos anteriores no Paraná: a greve dos servidores públicos estaduais (cerca de 100 mil professores) e a data de 29 de abril de 2015 causou impacto negativo em relação à profissão docente. "A forma truculenta como os políticos e policiais paranaenses trataram os trabalhadores da educação ficaram registradas na memória dos brasileiros". (WOITOWICZ, 2015, p. 50).

Outro aspecto a ser evidenciado na profissão "Professor" é o chamado "malestar docente". O "mal-estar docente" é, segundo Esteve (1999, p. 25), "expressão utilizada para descrever os efeitos permanentes de caráter negativo que afetam a personalidade do professor como resultado das condições psicológicas e sociais em que exerce à docência". O docente cada vez mais se vê diante de inúmeras situações novas às quais precisa adaptar-se, entre elas demandas e pressões externas (família, ambiente, meio social, tecnologia, trabalho/escola). 


\section{EVASÃO NA LICENCIATURA EM GEOGRAFIA NA UNIOESTE: CAMPUS DE MARECHAL CÂNDIDO RONDON}

A evasão discente nas licenciaturas é problema nacional, que afeta parte das Universidades do Brasil. De acordo com o Censo da Educação Superior 2013, na área educacional, foram matriculados 1.371 .767 estudantes, dos quais apenas 201.011 concluíram o ano matriculados.

Essa defasagem, não atribuída apenas a Unioeste, está contribuindo para a falta de docentes em áreas educacionais do ensino básico brasileiro. Nesse sentido, para discorrer sobre a problemática enunciada, procurou-se compreender e verificar os motivos da evasão escolar no ensino superior, especialmente nas licenciaturas.

Nesse contexto, objetivou-se: conhecer o perfil do evadido, compreender se o discente evadido desejava atuar na área que teria sido a de sua formação no curso ou pensava em outra profissão; verificar quais eram as expectativas anteriores à graduação, sobre o curso e sobre a atuação do profissional formado no curso, assim como se essas expectativas eram condizentes com a realidade; detectar e analisar a relação entre evasão escolar e trabalho, bem como evasão escolar com a vida pessoal; investigar os maiores obstáculos enfrentados pelos discentes evadidos durante o curso e o motivo principal para a evasão escolar; entender se os evadidos acreditam que algo poderia ter sido feito para evitar a evasão escolar; investigar se os evadidos voltariam ao mesmo curso e à mesma universidade; verificar como a evasão escolar repercutiu na vida dos evadidos; analisar a comunicação entre a Secretaria Acadêmica, o Colegiado de Curso e discentes evadidos; verificar a situação acadêmica atual. Contudo, para este artigo, não foram incorporados todos os questionários, mas questões vinculadas diretamente à temática proposta.

Assim, os dados preliminares foram coletados através de informações cedidas pela Secretaria Acadêmica da Unioeste, além de entrevistas com os discentes evadidos do Curso de Licenciatura em Geografia, Campus de Marechal Cândido Rondon, entre os anos de 2012 a 2015. Foi possível verificar que o número de ingressantes no curso supracitado totalizou em 146 discentes (Figura 2). Destes, 35\% estavam cursando, $53 \%$ se evadiram do curso e $12 \%$ nomeados "outros" são considerados os discentes inativos, que trancaram o curso, realizaram transferência interna e estão formados. 
Figura 2 -Total de discentes evadidos e cursando

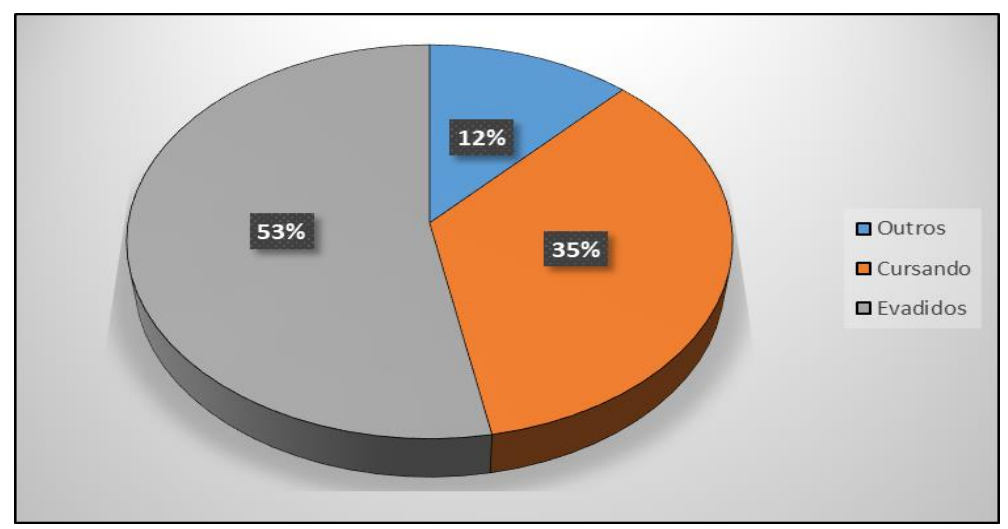

Fonte: Elaborado pela autora (2017)

Segundo dados da Secretaria Acadêmica da IES, o número total de evadidos entre os anos supracitados é de 77 , sendo que 08 discentes evadidos (12\%) não foram localizados. Estabeleceu-se contato com 69 discentes, destes, $6 \%$ se recusaram a responder, $17 \%$ não retornaram e $77 \%$ responderam.

Diante da aceitação e da participação na pesquisa, o primeiro item a discutir após os questionários e entrevistas refere-se à variável "gênero" e à variável "idade" dos discentes evadidos. Em relação ao gênero dos respondentes, predomina maior índice de evasão em discentes do sexo masculino (Figura 3), com cerca de $57 \%$, ou seja, 44 evadidos. 0 sexo feminino contempla 33 casos de evasão ou $43 \%$.

\section{Figura 3 - Variável de gênero dos discentes evadidos}

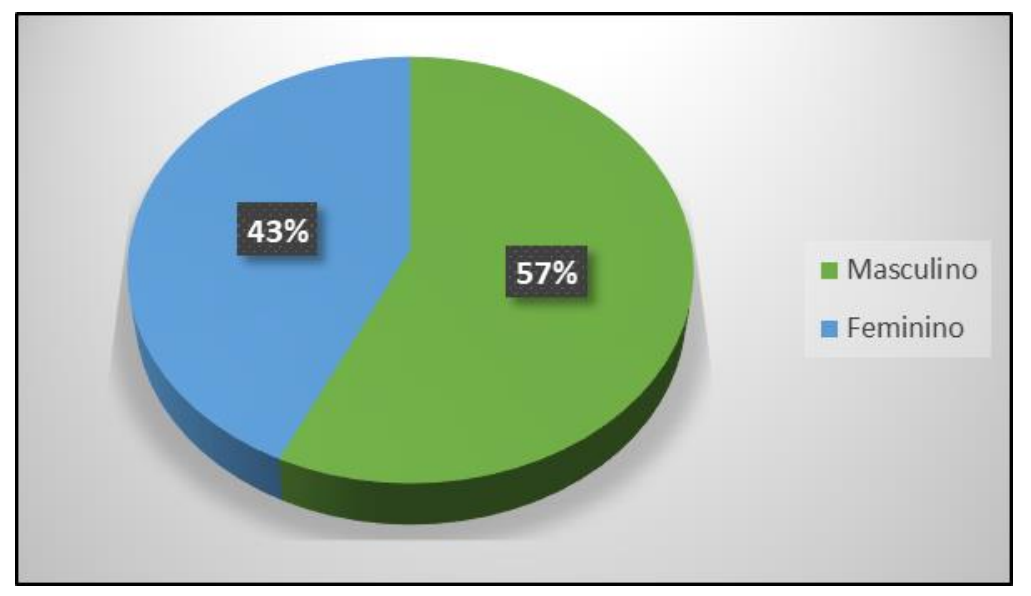

Fonte: Dados elaborados pela autora (2017)

Para a compreensão da evasão segundo a faixa etária dos respondentes, organizou-se a Tabela 01 . Destaca-se que $57 \%$ ou 30 discentes possuíam idade entre 
17 a 20 anos no momento da evasão. Para os discentes com idade entre 21 a 25 anos, aponta-se 08 respondentes evadidos ou 15\%. A faixa etária entre 26 a 30 anos demonstra 05 discentes ou 09\% e evadidos acima de 35 anos são 02 ou 04\% do total de respondentes.

Tabela 01 - Faixa etária dos discentes evadidos

\begin{tabular}{|c|c|c|}
\hline Idade & Discentes evadidos & Percentual \\
\hline Entre 17 e 20 anos & 30 & $57 \%$ \\
\hline 21 a 25 anos & 08 & $15 \%$ \\
\hline 26 a 30 anos & 05 & $09 \%$ \\
\hline 31 a 35 anos & - & - \\
\hline Acima de 35 anos & 02 & $04 \%$ \\
\hline NR & 08 & $15 \%$ \\
\hline Base de respondentes & 53 & $100 \%$ \\
\hline
\end{tabular}

Fonte: Dados coletados pela pesquisadora em janeiro de 2017

Nesse contexto, verifica-se que significativo percentual (57\%) de discentes evadidos possuía idade entre 17 a 20 anos, o que pode revelar um dos motivos da evasão: a imaturidade na escolha do curso. A formação universitária é um período de reativação das crises vocacionais, portanto, é período de confrontação com a realidade ocupacional e de firmação da escolha feita. Estudos mostram altos índices de indecisão entre os jovens ao estarem próximos de vestibulares, ou no início do curso, o que demonstra a fragilidade da decisão tomada inicialmente na adolescência (BARDAGI, 2007).

Esses aspectos tornam-se evidentes ao analisar o total de evadidos entre os períodos/anos cursados, conforme aponta a Figura 4.

Figura 4 - Concentração de evadidos entre os períodos/anos cursados

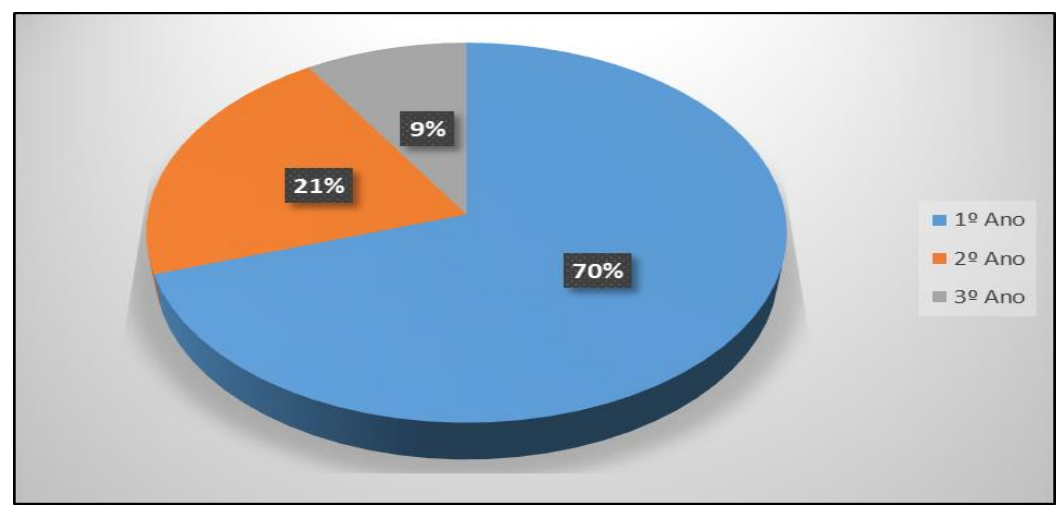

Fonte: Dados coletados pela pesquisadora em janeiro de 2017 
Como afirmado anteriormente, os dados revelam que, dos 53 evadidos respondentes, 37 discentes ou $70 \%$ abandonaram o curso no primeiro ano, 11 ou $21 \%$ no segundo ano e 05 ou $09 \%$ no terceiro ano.

Em relação ao período em que ocorreram as maiores taxas de evasão, a pesquisa mostra concentração nos primeiros anos ou períodos, de modo a estagnar a partir do terceiro e do quarto ano.

Cabe destacar que outros cursos e universidades apresentam índices altos de evasão nos primeiros anos de graduação. Uma pesquisa desenvolvida no Campus Rondonópolis da Universidade Federal do Mato Grosso (UFMT), sobre a evasão dos Cursos de Administração, Ciências Contábeis, Ciências Econômicas e Sistemas de Informação, aponta que os discentes indicaram desistência no $1^{0}$ e $2^{\circ}$ semestre ou no $1^{0}$ ano dos referidos cursos.

Do mesmo modo, na Licenciatura em História da Universidade Federal do Mato Grosso do Sul (UFMS), aponta-se que dos 84 matriculados em 2011 e 2012, 47 discentes desistiram na passagem para o segundo ano. Ainda, em pesquisa desenvolvida no Campus de Cascavel da própria Unioeste, no Curso de Ciências Biológicas, dos 13 sujeitos considerados na parte qualitativa da pesquisa, $65 \%$ desistiram no $1^{0}$ ano e $20 \%$ no $2^{\circ}$ ano de curso.

Diante dessa reconfiguração, Veloso (2000) destaca que o elevado índice de evasão nos primeiros anos de curso pode estar relacionado com o baixo desempenho no ensino médio. Outro fator que pode associar-se à acentuada proporção de evasão no primeiro e segundo anos de curso é a idade versus maturidade dos ingressantes.

Em outras palavras, como se verifica nos índices do Curso de Licenciatura em Geografia, cerca da metade dos discentes evadidos no primeiro e segundo ano apresentavam faixa etária entre 17 a 20 anos. Tais constatações apontam para o fato de que, além do alto índice de evasão no primeiro e no segundo ano da graduação, paralelamente está presente o fator da pouca idade dos jovens evadidos. É possível apontar, então, que um dos motivos da evasão é a imaturidade desses indivíduos ao ingressarem no ensino superior.

A propósito dessas afirmações, destacam-se as considerações de Bardagi (2007, p. 28-29): 
torno da experimentação, teste de hipóteses e desempenho de papéis, delineando um processo de tradução do autoconceito em termos vocacionais. É um período de transição, em que a autoanálise das próprias características e habilidades é constante, e o autoconceito não é estável. As tarefas de desenvolvimento consistem em realizar uma ampla exploração das ocupações, traduzindo o autoconceito em escolhas ocupacionais/educacionais, trocando progressivamente uma escolha mais específica e a convertendo desta preferência numa realidade concreta, através da educação especializada e do ingresso ao mundo educacional.

Assim, as experiências e as informações disponibilizadas aos jovens no processo de adaptação nos primeiros anos na universidade são importantes para a permanência no ensino superior. Nesse sentido, a maneira como os discentes se integram no curso superior proporciona as condições para enfrentar os desafios e/ou amenizar o impacto das dificuldades na transição da escola para a universidade

Em linhas gerais, se observou diversas razões para o abandono do curso. Segundo os retornos (Figura 5) o principal desafio é a dificuldade de conciliar trabalho e universidade, pois $85 \%$ dos evadidos desenvolviam atividades remuneradas ao desistirem do curso.

\section{Figura 5 - Relação dos discentes evadidos que exerciam ou não atividade remunerada}

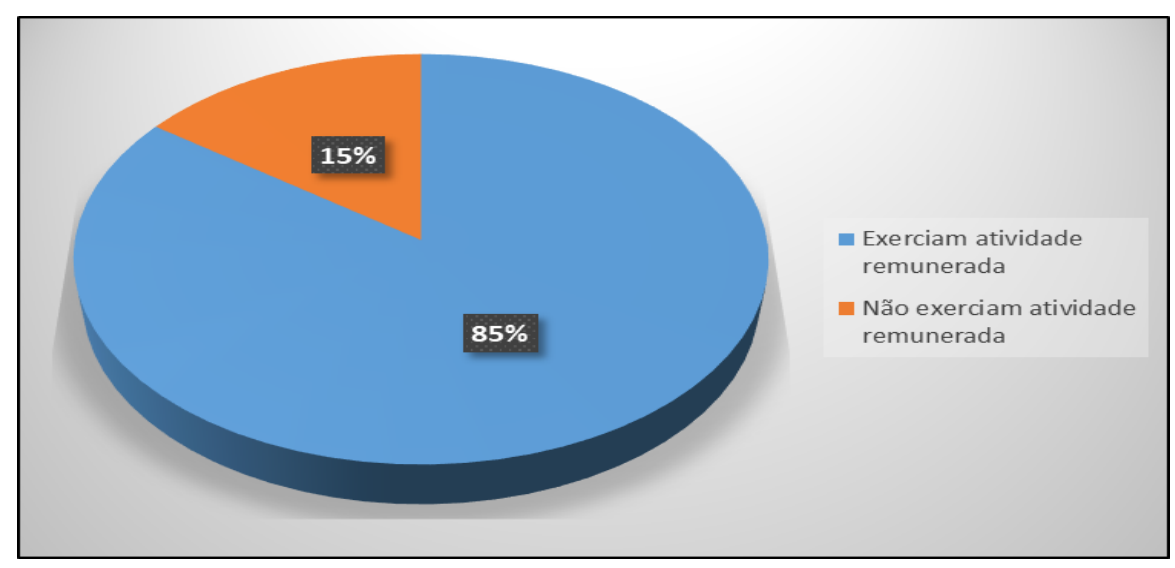

Fonte: Dados coletados pela pesquisadora em janeiro de 2017

Seguindo esse pressuposto, constatou-se que, apesar de tentar conciliar o trabalho com a universidade, parte dos estudantes trabalhadores não consegue se dedicar assiduamente ao percurso acadêmico. Como pode ser constatado nos dados apresentados, salienta-se que a maior parte dos evadidos tentava conciliar o trabalho com os estudos. Vale mencionar que, para esses discentes, o ingresso no ensino superior representa a possibilidade da qualificação profissional, de obter e manter-se no mercado de trabalho e de terem uma vida com qualidade, na perspectiva de futuro melhor (TERRIBILI FILHO, 2007). 
Pelo exposto, percebe-se que, de maneira geral, os discentes matriculados em cursos noturnos são provenientes de segmentos menos privilegiados economicamente (BERNARDO, 1996). Essa situação foi constatada na referida pesquisa, pois, dos 53 respondentes, 08 discentes não exerciam atividade remunerada durante 0 ingresso, ou seja, 45 evadidos trabalhavam e apresentavam reduzida disponibilidade de tempo para se dedicarem ao curso.

Nesse sentido, nota-se que as informações contidas na Figura 5 visam ilustrar um dos principais motivos para a evasão do curso: dificuldade de conciliação do trabalho com a universidade. Para firmar os dados, destacam-se respostas dos discentes evadidos:

"Trabalhava o dia inteiro, e depois que a greve voltou, o número de trabalhos subiu e eu não estava mais dando conta de fazer, por isso achei melhor desistir, já que o curso não me agradou, não iria fazer e ainda fazer tirando notas ruins" (E2015n);

"Não consegui conciliar trabalho e estudo" (E2012k);

"Bom, a faculdade era em outra cidade, e eu precisava trabalhar e estudar, começou a ficar um pouco puxado o tempo, entendeu" (E20121);

"O trabalho, pois não havia muito tempo para estudar" (E2013i);

"Meu trabalho... ou eu estudava ou trabalhava, como precisava de dinheiro, por que estudar tem que ter uma renda para o xerox e o ônibus, e logo depois fiquei grávida, ai que desisti de vez" (E2013m).

"Falta de tempo para trabalhos devido trabalhar 8 horas diárias e ter que assistir aula à noite e baixo rendimento" (E2015j).

"Falta de tempo para estudar devido ao trabalho" (E2015h).

Diante das respostas, constata-se que, apesar de tentar conciliar o trabalho com a universidade, parte dos estudantes trabalhadores não consegue se dedicar assiduamente ao percurso acadêmico. Assim, corrobora-se a ideia de Araújo (2009, p. 48), "o trabalho usurpou, penetrou nos poros da vida, ocupando parte do tempo e das preocupações do trabalhador, elevando o desgaste físico e mental".

\section{CONSIDERAÇÕES FINAIS}

Com este trabalho verificou-se e se analisou os principais motivos que levam os acadêmicos a abandonar seus estudos antes da conclusão prevista. Ainda, objetivou- 
se identificar o perfil dos discentes responsáveis pela crescente taxa de evasão, e conhecer a situação do aluno após a evasão.

Em primeiro lugar, constatou-se que o fenômeno da evasão no Curso de Licenciatura em Geografia da Unioeste de Marechal Cândido Rondon apresenta maior proporção do que a percepção geral que dela se tem. Levando-se em conta os dados obtidos, relativos aos anos de 2012 a 2015, o número total de ingressantes é de 146, dos quais, $53 \%$ se evadiram.

Uma das razões mais fortes para o abandono do curso, segundo os retornos dos depoimentos, é a dificuldade de conciliar trabalho e universidade, pois $85 \%$ dos evadidos desenvolviam atividades remuneradas ao desistirem do curso. Outro fator é que se verifica participação reduzida dos ex-alunos na vida interna da universidade, seja por falta de tempo, seja por falta de informações sobre seu funcionamento e espaços de atuação dos alunos na instituição.

Com base nas análises apresentadas neste artigo, pode-se salientar que compreender o significado da evasão na formação docente envolve produção de conhecimento e deve ser tratada com toda sua complexidade e potencialidade. Aponta-se a relevância de não permanecer simplesmente nos números e nos dados estatísticos, mas buscar identificar e conhecer os motivos e as causas do problema que desencadeiam a evasão nas licenciaturas, uns frequentes, outros inusitados, 0 que, independentemente de qual for, devem ser verificados e analisados.

Nesta seção que finaliza a escrita, a propósito das informações sistematizadas com o presente trabalho, destaca-se que foram desenvolvidas reuniões no Colegiado do curso supracitado, com interações dos representantes do C.A, bolsistas do PIBID e docentes, de modo a discutir propostas para que se possa buscar pela intervenção e minimizar as causas da evasão.

Dessa maneira, através da análise, da compreensão integrada e entendimento entre as partes (universidade e aluno), pode-se desenvolver à articulação de ações institucionais e sociais para a promoção contínua do processo de ensinoaprendizagem e permanência do Curso de Licenciatura em Geografia. 


\section{REFERÊNCIAS}

ADACHI, A. A. C. T. Evasão e evadidos nos cursos de graduação da UFMG. 2009. 214p.Dissertação (Mestrado em Educação) - Faculdade de Educação, Universidade Federal de Minas Gerais (UFMG), Belo Horizonte-MG.

ANDRÉ, M.E.D.A. Texto, contexto e significado: algumas questões na análise de dados qualitativos. Cadernos de pesquisa, Vol.45, n.1, p. 66-71, 1983. Disponível em:http://publicacoes.fcc.org.br/ojs/index.php/cp/article/view/1491. Acesso em: 15 abr. 2015.

ARAUJO, R.M.L. Instituições de formação profissional - história e perspectivas: o projeto da nova institucionalidade da educação profissional brasileira dos anos 1990. Rev. Ensaio: Avaliação e Políticas Públicas em Educação, Rio de Janeiro, mar. 2014, v.22, n.82. Disponível em: http://www.scielo.br/scielo.php?script=sci_arttext\&pid=S010440362014000100010. Acesso em: 20 mar. 2018.

BAGGI, C. A. S. \& LOPES, D. A. Evasão e avaliação institucional no ensino superior: uma discussão bibliográfica. Avaliação, Campinas/Sorocaba, v. 16, n. 2, p. 355-374, jul. 2011.

BARDAGI, M. P. Evasão e comportamento vocacional de universitários: estudos sobre o desenvolvimento de carreiras na graduação. 2007. 242p. Tese (Doutorado em Psicologia) - Universidade Federal do Rio Grande do Sul, Rio Grande do Sul, Porto AlegreRS..

BERNARDO, M.V.C. et al. O Ensino noturno na UNESP. São Paulo: UNESP/Pró-Reitoria de Graduação,1996.

BRASIL / MEC / SESU. Secretaria de Educação Superior / Ministério da Educação. Comissão Especial de Estudos sobre a Evasão nas Universidades Públicas Brasileiras. Brasília, 1996/1997 Disponível em: http://www.andifes.org.br/wpcontent/files_flutter/Diplomacao_Retencao_Evasao_Graduacao_em_IES_Publicas1996.pdf. Acesso em: 25 out. 2016.

BRASIL. RESOLUÇÃO CNE/CP No 2, DE 22 DE DEZEMBRO DE 2017. Institui e orienta a implantação da Base Nacional Comum Curricular, a ser respeitada obrigatoriamente ao longo das etapas e respectivas modalidades no âmbito da Educação Básica. Disponível em:

http://basenacionalcomum.mec.gov.br/images/historico/RESOLUCAOCNE_CP222DEDEZEM BRODE2017.pdf. Acesso em: 25 set. 2018.

BRASIL. LEI No 13.415, DE 16 DE FEVEREIRO DE 2017. Altera as Leis n 0 9.394, de 20 de dezembro de 1996, que estabelece as diretrizes e bases da educação nacional, e 11.494, de 20 de junho 2007, que regulamenta o Fundo de Manutenção e Desenvolvimento da Educação Básica e de Valorização dos Profissionais da Educação, a Consolidação das Leis do Trabalho - CLT, aprovada pelo Decreto-Lei no 5.452, de $1^{\circ}$ de maio de 1943, e o Decreto-Lei no 236, de 28 de fevereiro de 1967; revoga a Lei $n^{\circ} 11.161$, de 5 de agosto de 2005; e institui a Política de Fomento à Implementação de Escolas de Ensino Médio em 
Tempo Integral. Disponível em: http://www.planalto.gov.br/ccivil_03/_Ato20152018/2017/Lei/L13415.htm. Acesso em: 25 set. 2019.

CASTRO, L. P. V. Evasão Escolar no Ensino Superior: Um estudo nos Cursos de Licenciatura da Universidade Estadual do Oeste do Paraná - UNIOESTE - Campus Cascavel. 2013. 168p. Dissertação (Mestrado em Educação) - Universidade Estadual do Oeste do Paraná (UNIOESTE), Cascavel-PR.

ESTEVE, J. M. 0 mal estar docente: a-sala-de-aula e a saúde dos professores. Tradução Durley de Carvalho Cavicchia. Bauru, SP: EDUSC, 1999.

FERRETI, C. J.; SILVA, M. R. Reforma do ensino médio no contexto da medida provisória no 746/2016: Estado, currículo e disputas por hegemonia. Revista Educação. Sociedade, Campinas, v. 38, n. 139, p. 385-404, abr./jun. 2017.

FRIGOTTO, G. A gênese das teses do Escola sem Partido: esfinge e ovo da serpente que ameaçam a sociedade e a educação. In: FRIGOTTO, G. (Org.). Escola "sem" partido: esfinge que ameaça a educação e a sociedade brasileira. Rio de Janeiro: UERJ, 2017. p. 17-34.

GAIOSO, N. P. L. O fenômeno da evasão escolar na educação superior no Brasil. 2005. 75 p. Dissertação (Mestrado em Educação) Universidade Católica de Brasília (UCB), Brasília-DF.

GADOTTI, M. Concepção dialética da educação e educação Brasileira contemporânea. In: Educação e Sociedade. CEDES, nº 8. São Paulo: Cortez, 1981.

GIL, A. C. Como elaborar projetos de pesquisa. São Paulo: Atlas, 2008.

HERMIDA J. F.; LIRA. J. S. Imagens e Palavras. Políticas Educacionais em Tempos De Golpe: Entrevista com Dermeval Saviani. Revista Educação e. Sociedade. vol.39 n.144, Campinas jul./set. 2018. Disponível em: https://www.cedes.unicamp.br/publicacoes/edicao/824. Acesso em: 25 out.2019.

HICKMANN, J. Opção pela licenciatura no curso de Ciências Biológicas: fatores envolvidos na escolha. 2007. 98p. Monografia (Conclusão de Curso) Curso de Ciências Biológicas. Universidade Estadual do Oeste do Paraná (UNIOESTE), Cascavel-PR.

INEP. Resumo Técnico: Censo da Educação Superior - 2013. Ministério da Educação, Brasília, DF, 2014. Disponível em: . Acesso em: 20 mar. 2016.

LOBO, M. B. C. M. Panorama da evasão no ensino superior brasileiro: aspectos gerais das causas e soluções. ABMES Cadernos, v.1, n. 25, 2012.

MEC/ANDIFES/ABRUEM/SESU. Diplomação, retenção e evasão nos cursos de graduação em instituições de ensino superior públicas. Avaliação, Campinas, v.1, n. 2, p. 55-65, jul. 1996.

MARTINS. M. C. Base Curricular é conservadora, privatizante e ameaça autonomia, avaliam especialistas. Jornal da UNICAMP. Caminas, Dez. 2017. [Entrevista concedida a Manuel Alves Filho]. Disponível em: 
https://www.unicamp.br/unicamp/index.php/ju/noticias/2017/12/04/base-curricular-econservadora-privatizante-e-ameaca-autonomia-avaliam. Acesso em: 22 out. 2019.

MINAYO, M. C. de S. (org.). Pesquisa Social. Teoria, método e criatividade. 18 ed. Petrópolis: Vozes, 2001.

NOTA PÚBLICA DA ANPED SOBRE A MEDIDA PROVISÓRIA DO ENSINO MÉDIO. Set. 2016. Disponível em: http://www.anped.org.br/news/nota-publica-da-anped-sobre-medidaprovisoria-do-ensino-medio. Acesso em: 25 set. 2019.

PERONI, V.; CAETANO, M. R.; LIMA, P. Reformas educacionais de hoje: as implicações para a democracia. Revista Retratos da Escola, Brasília, DF, v. 11, n. 21, p. 415-432, jul./dez. 2017.

POLYDORO, S. A. 0 trancamento de matrícula na trajetória acadêmica do universitário: condições de saída e de retorno à instituição. 2000. 145p. Tese (Doutorado em Educação) - Universidade Estadual de Campinas (Unicamp), Campinas-SP.

PONTUSCHKA, N.N. Políticas públicas na trajetória do ensino e da formação dos professores: a construção de conhecimentos. In: ALBUQUERQUE, Maria A. M. \& FERREIRA, Joseane A. S. (Orgs.). Formação, pesquisas e práticas docentes: reformas curriculares em questão. João Pessoa: Mídia, 2013. p. 433-453.

SANTIAGO, A.R.F; CALLAI, H.C. O protagonismo social e a força do lugar nas políticas públicas de educação. In: SANTIAGO, Anna Rosa Fontella; CALLAI, Helena Copetti (Org.). Educação no contexto da globalização: reflexões a partir de diferentes olhares. Ijuí: Ed. Unijuí, 2014.

RIBEIRO, M. A. O projeto profissional familiar como determinante da evasão universitária: um estudo preliminar. Revista Brasileira de Orientação Profissional, 6(2), p. 55-70.

SILVA FILHO, R. L. L. et al. A Evasão no Ensino Superior Brasileiro. Cadernos de Pesquisa, São Paulo. v. 37 n. 132, p. 641-59, set./dez. 2007.

TERRIBILI FILHO, A. Educação superior no período noturno: impacto do entorno educacional no cotidiano do estudante. 2007. 186p. Tese (Doutorado em Educação) Universidade Estadual Paulista, Faculdade de Filosofia e Ciências (UNESP), Marília-SP. Disponível em: http://200.145.6.238/handle/11449/104842. Acesso em: 10 jan. 2016.

UNIOESTE. Resolução 069/2004. Aprova alteração da Seção I, do Capítulo I - Título VI, e do Capítulo I, do Título VIII, da Resolução no 028/2003 (Regimento Geral da UNIOESTE). Conselho Universitário, Universidade Estadual do Oeste do Paraná, Cascavel, 2003. Disponível em: http://www.unioeste.br/servicos/arqvirtual. Acesso em: 13 fev. 2015.

VELOSO, T. C. M. A. A evasão nos Cursos de Graduação da Universidade Federal de Mato Grosso, Campus Universitário de Cuiabá 1985/2 a 1995/2 - um processo de Exclusão. Cuiabá, 2000, 123 p. Dissertação (Mestrado em Educação) - Universidade Federal do Mato Grosso (UFMT), Cuiabá-MT.

WILHELM, M. F. A Evasão dos Cursos de Licenciatura em Geografia da Universidade Estadual do Oeste do Paraná (UNIOESTE). 2019. 185 f. Dissertação 
(Mestrado em Geografia) - Universidade Estadual do Oeste do Paraná (UNIOESTE), Francisco Beltrão-PR.

WOITOWICZ, E. A formação inicial de professores de Geografia no PIBID / UNIOESTE - Campus de Marechal Cândido Rondon-PR (2011-2015). 2016. 144 p. Dissertação (Mestrado em Geografia) - Universidade Estadual do Oeste do Paraná (UNIOESTE), Francisco Beltrão-PR. 